OPEN ACCESS

Edited by:

Anupam Sule,

St. Joseph Mercy Oakland Hospital,

United States

Reviewed by:

S. Suresh

Sona College of Technology, India

Michael Dohan,

Lakehead University, Canada

*Correspondence:

Joseph Tan

tanjosep@mcmaster.ca

Specialty section:

This article was submitted to

Digital Public Health,

a section of the journal

Frontiers in Public Health

Received: 08 September 2021

Accepted: 26 January 2022

Published: 18 February 2022

Citation:

Ye P, Liu L and Tan J (2022)

Influencing Factors on College

Students' Willingness to Spread Internet Public Opinion: Analysis

Based on COVID-19 Data in China.

Front. Public Health 10:772833.

doi: 10.3389/fpubh.2022.772833

\section{Influencing Factors on College Students' Willingness to Spread Internet Public Opinion: Analysis Based on COVID-19 Data in China}

\author{
Pinghao Ye ${ }^{1}$, Liqiong Liu ${ }^{1}$ and Joseph Tan ${ }^{2 *}$ \\ ${ }^{1}$ School of Information Engineering, Wuhan Business University, Wuhan, China, ${ }^{2}$ DeGroote School of Business, McMaster \\ University, Hamilton, ON, Canada
}

Following COVID-19 outbreak, Internet public opinion has tended to proliferate. From a theoretical perspective, however, the spread law of Internet public opinion in major epidemic prevention and control may provide optimization strategies on how best to channel Internet public opinion. Specifically, this article aims at exploring key factors affecting our theoretical understanding on the spread of Internet public opinion on a major epidemic situation amongst college students. A questionnaire survey on college students was conducted via online research data collection platform located in Changsha, China, amassing three hundred and nineteen valid questionnaires. Smart PLS was applied to verify a theoretical model vis-à-vis the reliability and validity of the measuring instrument. Results show that adult attachment and social motivation have significant positive influences on the consciousness of social participation. Evidently, adult attachment, emotional orientation and risk perception also have significant positive influences on emotional motivation. Emotional motivation plays a mediating role in the relationship between affective disposition and dissemination willingness. Additionally, social motivation, consciousness of social participation and emotional motivation significantly influence one's dissemination willingness in a positive way. The consciousness of social participation plays a mediating role in the relationship between social motivation and dissemination willingness. Social motivation plays a moderating role in the relationship between risk perception and dissemination willingness. Altogether, theoretical rationalization to enhance understanding and guide the initiation and spread of Internet public opinion of major public health emergencies accurately has now been provided by this work.

Keywords: adult attachment (AA), COVID-19, emotional motivation (EM), epidemic prevention, public opinion, social motivation (SM)

\section{INTRODUCTION}

Today, the Internet comfortably eases users in gathering a wealth of information and has oftentimes become the main choice and the vehicle that people use to seek health knowledge (1). Even so, there are risks and hidden dangers; for instance, online rumors and fake health news have flooded public opinion forums. Various published articles on health, spread of epidemics and treatment methods have appeared on social media; sadly, the sources and contents of these articles are often vague and may not be easily affirmed. 
Distinguishing facts (the truth) from rumors (the fake) has become challenging. Information receivers often have difficulties finding the truth $(2,3)$. When health-related rumors wantonly spread and behave like viruses, they will instill unnecessary anxiety to users and instigate troubles onto their lives (4). Inaccurate health information from some alarmists will arouse the public's psychological panic and gradually destroy the social trust system. Accordingly, researchers should attach great importance to studying the spread of health information.

COVID-19 is a notable type of acute respiratory tract infectious disease with entire populations to be generally susceptible. On January 30th, 2020, the World Health Organization (WHO) declared that COVID-19 was an international public health emergency (5). COVID-19 poses a great threat to the safety as well as physical and mental health of the public due to its high infectiousness, deadliness and uncertain treatment strategies (6). During a period of major epidemic prevention and control, the Internet has become a key channel for the masses to understand the progress of epidemic prevention and control and information related to the epidemic situation (7). Without a rational, scientifically sound, and effective public opinion guidance and governance, public opinion expressed on the Internet may evolve into informed public opinion, and the crisis caused by it is equivalent to the threat and panic from major epidemic situation. Accordingly, the internet public opinion on a major epidemic and its governance practice should be studied meticulously and particularly from a theoretical perspective as purposed by the effort presented herein.

The effect of COVID-19 on the social economy and psychology of the masses has attracted the attention of many scholars, including the influence of COVID-19 on citizens' psychology (8); the effect of COVID-19 on the public health management (9); and the effect of COVID-19 on the regional and national economic development (10). Since the outbreak of COVID-19, major Internet events have endlessly emerged, and Internet public opinion has been rapidly formed and fermented. College students, as a special group, are the hope of each family and respective country. These students are the frontier group clearly exposed to the use of new technologies and opened to new ideas in society owing to their active thinking and skilful use of the Internet for gathering new information. College students in contact with new things can often quickly accept information and adapt to the changes in the environment.

The psychosocial cognition of these students on COVID-19 is relatively high (11). To a great extent, the cognition and attitude of college students toward the epidemic situation not only determine their own physical and mental health but also affect the surrounding population (11). Focusing on college students' knowledge, attitude and behavior on the COVID-19 epidemic situation and understanding the coping style of college students in major epidemic prevention and control from a theoretical perspective can therefore provide key information anchors for understanding major epidemic prevention and control. These mechanisms are also conducive to endorsing the significant role of college students in major epidemic prevention and control. The public can correctly understand the knowledge on major epidemic situation and improve the self-protection ability via extensive and in-depth health education. Accordingly, the normal social order may be maintained. Such approach can also promote the protection of public health emergencies (12).

In this work, we take college students as the objects to be investigated. We analyse the spread characteristics of Internet public opinion (IPO) in the prevention and control of COVID-19 and construct a structural equation model vis-à-vis a constructive theoretical approach. Moreover, we deploy an empirical analysis to validate those key theoretical factors affecting the IPO spread on a major epidemic situation amongst college students. Hence, this work offers a much-needed theoretical support for the government (and other policymakers) in the management of IPO and the formulation of countermeasures.

This study comprises eight parts. First, the research background, research significance and research content of key influencing factors on IPO on a major epidemic prevention and control are introduced. Second, the research literature on IPO regarding major epidemic prevention and control is summarized. Here, a theory-based research model of influencing factors affecting college students' IPO spreading on major epidemic prevention and control is constructed. Third, research hypotheses are proposed and rationalized. Fourth, the variables and measurement questions embedded in the research model are highlighted. As well, we determine the questionnaire and research method, and explain the data analytical method to be applied in the study.

Fifth, the valid questionnaire samples collected are analyzed and the conclusion of this paper is drawn. Sixth, we systematically analyse and summarize the conclusion of this study. Seventh, the major theoretical significance of this study is then explored. Finally, the study limitations and future research prospects are discussed.

\section{BACKGROUND}

\section{The Influence of the COVID-19 Outbreak on College Students' Access to Information}

The psychosocial cognition of college students' on COVID19 is positively correlated with active coping while negatively correlated with negative coping. The college students with high cognition are likely to take active coping measures (13). This notion indicates that improving the cognition on the disease can aid individuals to respond positively. Approximately $84.0 \%$ of college students believe that the government has taken positive and effective measures, recognized the efforts made by the authorities and have confidence in the mandated epidemic prevention and control efforts (14). Purportedly, 95.8\% of college students have collected information about COVID-19 via WeChat and microblog. Still, $83.0 \%$ of college students have collected information about COVID-19 epidemic situation via $\mathrm{TV}$ and radio. The emerging media, represented by WeChat and microblog, are characterized by instant communication, popularity of the main body and visualization of pictures and texts. Such platforms have broadened the learning channels of college students and meet the psycho-socio needs of college 
students. Thus, new media have become the main channel for college students to acquire epidemic information.

\section{The Influence of the COVID-19 Outbreak on College Students' Psychology}

The psychological mood of college students is greatly affected due to rising pressures from diverse sources. For example, the implementation of strict home quarantine causes many college students to stay at home. Often characterized as in the psychological development stage, these students are likely to develop negative psychological emotions, such as depression, anxiety, and stress, due to undue pressures both from the epidemic and long hours of study. In serious cases, these emotions can even affect the students' health. Depending on the environmental circumstances, the prevalence rates of PTSD (Post-Traumatic Stress Disorder) and depression during the outbreak range from 2.7 to $9.0 \%$ (15). If college students are in their fourth year (the year of graduation), and live in seriously affected areas, then extreme fear is the key influencing risk factor causing psychological distress, followed by short sleep time.

Odriozola-González et al. (16) investigated the psychological wave of Spanish University of Valladolid during the outbreak. About $50.43 \%$ of the interviewees said that they were moderately affected, some even severely. Students majoring in the arts and humanities, social sciences and law had higher scores in anxiety, depression, and stress, whilst those majoring in engineering and architecture have lower scores. The clinical depression cases increased by $25-30$ times due to the closure measures taken during the outbreak, and the number of Greek college students with suicidal thoughts increased by eight times (17). One third of people accepted the theory that COVID-19 was conspiracy. The study results especially emphasized the need to take specific intervention measures for the mental health of disadvantaged groups.

Put simply, investigating the knowledge of college students on COVID-19 and analyzing their attitudes toward epidemic prevention and control measures will be key to unlock and improve our understanding of how best to prevent and hinder the spread of COVID-19 among college students, as well as how best to plan on beneficial and impactful educational interventions for them (18). The COVID-19 had a greater impact on the psychology and sleep of college students $(19,20)$. Virtual mentorship pairing was the highest rated educational intervention suggested by first- and second-year medical students. The third- and fourth-year medical students had frequently cited virtual surgical skills workshops (21). The prevalence rates of anxiety and depression were 7.7 and $12.2 \%$, respectively (22). The study results of (23) showed that the incidence of somatic symptoms amongst college students was 34.85 (mild, 26.26\%; moderate, $8.59 \%$ ). The incidence of somatic symptoms in primary school students was $2.39 \%$ (all mild).

Amongst the entire cohort, concern regarding COVID19 was positively correlated with the occurrence of somatic symptoms. Somatic symptoms were likely amongst college students expressing greater concern regarding the threat to life and health posed by COVID-19 and the efficacy of prevention and control measures. Approximately $70 \%$ of learners reported that they were involved in e-learning during the lockdown. Most learners used android mobile in e-learning environments (24). Students have been facing various problems related to depression anxiety, poor internet connectivity and unfavorable study environment at home. Importantly, students who face enormous challenges in their studies during this pandemic come mainly from remote areas and marginalized sections of society.

The outbreak of the epidemic increased the loneliness of overseas students and affected their career development (25). With the outbreak of the epidemic, a stable family income and living with parents could effectively reduce anxiety (26). Economic effect aside, the impact on daily life and academic delay are also positively correlated with anxiety, whilst social support is negatively correlated with anxiety (27). Savitsky et al. (28) studied the influence of COVID-19 on the psychology of nursing students. Their results showed that female gender, lack of personal protective equipment (PPE) at work and being a parent were significantly associated with high anxiety scores. Zhang et al. (29) studied the influence of COVID-19 on the psychology of international students in Medical Bachelor, Bachelor of Surgery of Zhejiang University. Even though students' knowledge on Traditional Chinese Medicine (TCM) and their discussion and consultation behaviors have been significantly improved, and students' understanding on the necessity of TCM has been significantly enhanced based on the online Chinese medicine courses, most students still preferred face-to-face classroom learning compared to online learning.

\section{Analyzing Causes of Major IPO}

In general, researchers believe that major IPO is the product of the comprehensive action of various social factors, and they can explore the causes from various aspects, including the subject and object of public opinion, media, social environment, contingency factors and the manifestation of public opinion (30).

Briefly, some scholars analyzed the causes of IPO from four dimensions, including political and economic reasons, social environment and hot events, false and bad information dissemination, the strong media influence of new media era $(31,32)$. Also, some scholars analyzed the configuration of the influencing factors on IPO and found that maintaining high sensitivity of information source, high participation of Internet users and/or high media activity and high government intervention can stimulate the generation of a heat index of high public opinion $(33,34)$. In the study reported herein, we investigated the causes of generating a major IPO from specific fields.

The first cause includes objective and realistic factors. The IPO is an inevitable product of the frequent occurrence of social public events. The sudden public events will cause great psychological influence on the public $(35,36)$. The second comprises government intervention factors. If the timeliness of government intervention is worse, and the intervention level is high, then the heat of IPO is high. The heat of public opinion events responded by the government via press conference and social media is high $(37,38)$. The third involves the psychological factors of public opinion subjects. The optimistic mood of netizen 
and the pessimism of the government can bring favorable results to the development of public opinion, and the influence of the emotional state and intensity of the government is great (39).

\section{RESEARCH MODEL AND HYPOTHESES}

A key characteristic of modern democratic society is social participation, which refers mainly to the direct participation and influence of the public on social and public affairs (40). The social participation mechanism, a type of participatory democracy, is a process and approach to achieve societal growth via active participation into social development activities based on the public's concern for their own interests and their conscious recognition on social public interests and public objects (41). Hence, the following hypotheses are put forward in this study:

\section{H1: AA Has a Significant Positive Influence on the Consciousness of One's Social}

\section{Participation}

Adult attachment (AA) is a sustained and long-term emotional connection between adult individual and current peers and a stable interpersonal interaction style of the individual (42). Hence, it can influentially affect the consciousness of one's social participation in a positive manner.

\section{H2: SM Has a Significant Positive Influence on the Consciousness of One's Social Participation}

Different scholars have conceptualized how social motivation (SM) can influence or affect people differently. While HilvertBruce et al. (43) believed that SM is the basic force driving people's social behavior, and Hernandez et al. (44) believed that $\mathrm{SM}$ is an internal motivation that promotes individual activities to achieve a certain goal. Based on the dictionary of psychology (45), we purport that SM is the psychological tendency of individuals to engage in certain activities to meet their own social needs, which is directly related to their social needs, but not to their physiological needs. Hence, it can surely influence the consciousness of one's social participation.

\section{H3: IAD Has a Significant Positive Influence on the Consciousness of One's Social Participation}

Information affective disposition (IAD) refers to the college students' inner emotional attitude toward the text when they are reading the major epidemic information. Therefore, it too can certainly influence the consciousness of one's social participation as well as one's emotion, which is linked invariably to $\mathrm{H} 4$ below.

\section{H4: IAD Has a Significantly Positive Influence on Emotional Motivation (EM)}

Emotional motivation (EM) refers to the condition wherein people release public crisis information to express emotions. After the outbreak of a major epidemic, the public's psychology, emotion, and belief will be affected to different extents. Individuals in such crisis situations are prone to have panic, depression, anxiety, and other negative emotions. The public can reduce anxiety and vent discontent based on the information transmission via the Internet $(46,47)$. The public will often express their feelings to relatives, friends, and even strangers via real-time dissemination of information to seek comfort, understanding and spiritual support to alleviate the inner uneasiness in the crisis situation or release the dissatisfaction with the crisis management stakeholders (48). Hence, as noted in the discussion for $\mathrm{H} 3$, IAD will certainly also influence one's emotional motivation.

\section{H5: AA Has a Significantly Positive Influence on EM}

Emotional catharsis is a form of public right of discourse and participation, which is conducive to the self-regulation of personal emotions in crisis situations, seeking self-comfort and psychological balance (49). Not surprisingly, we can speculate that AA, which projects one's attachment to others' emotions and related feelings, to influence one's EM significantly.

\section{H6: Risk Pereption Has a Significantly Positive Influence on EM}

Risk relates to the consideration of the possible loss or injury caused by objective facts $(50,51)$. EM has a significant influence on individual participation in social activities (52). Put together, risk perception, especially that is related to the risk that the dissemination of error messages will possibly lead to crime, will generally be heighten for the public when the loss or injury caused may be serious. Accordingly, such risk perception will assert an influence also on one's EM.

\section{H7: SM Has a Significantly Positive} Influence on the Dissemination Willingness

As indicated, SM or one's psychological tendency to engage in certain activities to meet one's social needs can play a critical role in the dissemination of information. Since the 1970s, emotion study has blossomed into a new discipline. Exploring key influencing factors on microblog users' participation in interaction, Stuart and Martin (53) found that perceived usefulness and expectation confirmation significantly affect users' willingness to use.

\section{H8: The Consciousness of Social Participation Has a Significantly Positive} Influence on the Dissemination Willingness

Weingart et al. (54) analyzed the intention of dissemination vis-àvis the theory of SM and pointed out that personal needs, interest promotion, self-expression and self-actualization are the main motivations to influence the intention of dissemination.

\section{H9: EM Has a Significant Positive Influence on the Dissemination Willingness}

As well, the theory of EM proposed by Auguste Comte, a famous French philosopher and the founder of sociology and positivism, tells us that emotion, behavior, and talent comprise humanity. Emotion is a decisive factor; as such, human emotion drives 
human reason and activity goal. Put simply, human behavior is mainly driven by EM. Hence, it is expected that EM will critically influence one's willingness to disseminate information.

\section{H10: Risk Perception Has a Significant Positive Influence on the Dissemination Willingness}

Cao et al. (55) analyzed the influencing factors of users' willingness to disseminate enterprise microblog information from the perspective of enterprise microblog marketing. Their results showed that the benefits and reputation increase positively affected their intention of dissemination.

\section{H11: EM Plays a Mediating Role in the Relationship Between Emotional Orientation and Dissemination Willingness}

Some scholars also analyzed users' motivation from the perspective of a microblog generation content (56). The research conclusions from Hsu and Lin (57) pointed out that the entertainment role, altruism and promotion of honor had a positive influence on the generation behavior of bloggers. The promotion of status positions and the sense of belonging had a significant influence on the continuous generation and sharing of a user content. Park et al. (58) indicated that the interest, usefulness, altruism, and identity have a significant influence on the generation behavior of video users.

\section{H12: Social Participation Consciousness Plays a Mediating Role in the Relationship Between SM and Dissemination \\ Willingness}

The social participation mechanism, a participatory democratic process and approach, achieves the growth and development of society via active participation into social development activities moderated by the concern of the public over their own interests and awareness respecting social public interests and public affairs (59). This approach is a code of conduct and norm for the entire society to discuss, consult and make decisions on social affairs $(60,61)$.

\section{H13: SM Plays a Moderating Role in the Relationship Between Risk Perception and Dissemination Willingness}

With the frequent occurrence of crisis and the development of democracy, the consciousness of crisis, political consciousness and the sense of participation are gradually strengthening. In public emergencies, public participation has become a new norm (62). The motivation of crisis information dissemination in a mobile Internet environment includes egoistic (emotional and social) motivation and altruistic (informational) motivation (63).

\section{RESEARCH METHODOLOGY}

\section{Sampling and Data Collection}

In this study, the questionnaire survey method was used to conduct empirical research and data collection. Chinese college students served as the objects investigated.

The questionnaire, designed according to the unified standards and requirements, was distributed online via WWW. WJX.CN, an online research data collection platform located in Changsha, China. This platform executes the questionnaire administration process and provides powerful data collection, storage, and analytical tools to deeply explore the value of data being collected. Presently, reported statistics on WWW.JX.CN indicated that about 83.15 million users have responded to over 6.55 billion questionnaires.

In this study, a total of 438 questionnaires were distributed, and 319 valid questionnaires were collected with an effective respond rate of $72.83 \%$. Descriptive statistics indicated that, amongst the valid samples, $48.6 \%$ were male, and $51.4 \%$ were female.

According to data shown in Table 1, the distribution of the objects investigated was as follows:

With respect to the "Grade" variable, first-year students (freshmen) accounted for $28.8 \%$, second-year students (sophomore) for 35.4\%, third-year students (junior) for $24.8 \%$ and forth-year students (senior) for $11 \%$.

In term of specialized subject, liberal arts students accounted for $36.7 \%$, those with science major for $34.8 \%$, those with engineering major for $26.3 \%$, and students of arts and sports for $2.2 \%$.

As for time spent online: $4.1 \%$ of college students surfed the Internet for $1-2 \mathrm{~h}$ daily, $28.5 \%$ surfed the Internet for 3-4 h daily,

TABLE 1 | Demographic characteristics of valid samples.

\begin{tabular}{llcc}
\hline Variables & Categories & Frequency & Percentage \\
\hline Gender & Male & 155 & $48.6 \%$ \\
Grade & Female & 164 & $51.4 \%$ \\
& Freshmen & 92 & $28.8 \%$ \\
& Sophomore & 113 & $35.4 \%$ \\
& Junior & 79 & $24.8 \%$ \\
Specialized subject & Senior & 35 & $11 \%$ \\
& Liberal arts & 117 & $36.7 \%$ \\
& Science & 111 & $34.8 \%$ \\
Online time every day & Engineering & 84 & $26.3 \%$ \\
& Arts and sports & 7 & $2.2 \%$ \\
Frequency of paying attention & 1-2h & 13 & $4.1 \%$ \\
to public opinion & 3-4h & 91 & $28.5 \%$ \\
& E-6h & 121 & $37.9 \%$ \\
& More than $6 \mathrm{~h}$ & 94 & $29.5 \%$ \\
& & 91 & $28.5 \%$ \\
& Often & 174 & $54.5 \%$ \\
& Occasionally & 52 & $16.3 \%$ \\
& Less & 2 & $0.6 \%$
\end{tabular}


$37.9 \%$ surfed for $5-6 \mathrm{~h}$ daily, and $29.5 \%$ of the students surfed for more than $6 \mathrm{~h}$ daily.

Regarding the frequency of paying attention to COVID-19 public opinion: $28.5 \%$ of college students paid attention to it daily, $54.5 \%$ of college students often paid attention to it, $16.3 \%$ of the students paid attention to it occasionally, and $0.6 \%$ of them paid less attention to it.

\section{Questionnaire and Measurements}

The questionnaire adapts multiple items from previously welldeveloped scales. It was also designed in strict accordance with the translation-back translation procedure. Altogether, the questionnaire has been appropriately adjusted through pretesting relevant questions, recognizing the actual situation of Chinese college students.

The comprehensibility of problem description was ascertained via interviews. The pre-survey questionnaire was issued according to the results. The questionnaire was further modified vis-à-vis the feedback of the pre-survey. The formal questionnaire was finally formed. Besides the investigation on the basic information of college students, the Likert 7 -scale was used to record the attitude of objects investigated toward various questions provided in the questionnaire. "1" represents strongly disagreed; "7" indicates strongly agreed.

The Affective Disposition (AD) Scale was adopted from the (64) questionnaire with the scale comprising two question items. The average score of all items in the scale was regarded as the $\mathrm{AD}$ measurement score. The $\mathrm{AD}$ was significant when the score was high. The Dissemination Willingness Scale was adopted from the (52) questionnaire with its scale having three question items. The average score of all items in the scale was regarded as the measurement score. The dissemination willingness of the objects investigated was strong when the score was high. The Emotional Motivation (EM) Scale was derived from the (65) questionnaire.
This scale contained two question items. The average score of all items in the scale was regarded as the EM measurement score. The EM of individuals was strong when the score was high.

The Adult Attachment (AA) Scale was derived from the (66) questionnaire; accordingly, this scale has three question items. The average score of all items in the scale was regarded as the AA measurement score. The AA of individuals was strong when the score was high. The Social Motivation (SM) Scale was derived from the (44) questionnaire, which contained two question items. The average score of all items in the scale was regarded as the SM measurement score. The SM of individuals was strong when the score was high. The Social Participation Consciousness Scale was drawn from the questionnaire designed by (67). This scale contained three question items. The average score of all items in the scale was regarded as the Social Participation Consciousness measurement score. This characteristic of individuals was strong when the score was high. In the Risk Perception Scale, the questionnaire designed by (68) was adopted. This scale contained two question items. The average score of all items in the scale was regarded as the risk perception measurement score. The risk perception of individuals was strong when the score was high. The final measurement items of seven constructs may be found in the Appendix.

\section{Reliability and Validity Analysis}

The reliability and validity of risk perception, dissemination willingness, AA, EM, and SM were analyzed by SPSS24.0 with results shown in Table 2. This table illustrates that the Composite Reliability (CR) of all potential variables to be more than 0.8 , and Cronbach's $\alpha$ coefficients of all variables are all higher than the recognized minimum level $(0.6)$. This indicates that all the scales have good reliability.

Exploratory factor analysis was used to test the construct validity of the scale. The factor load of each item corresponding

TABLE 2 | Reliability analysis.

\begin{tabular}{|c|c|c|c|c|c|}
\hline Construct & Item & Factor loading & Cronbach's $\alpha$ & CR & AVE \\
\hline \multirow[t]{2}{*}{ Affective disposition of information (ADI) } & ADI 1 & 0.821 & 0.677 & 0.858 & 0.752 \\
\hline & ADI 2 & 0.911 & & & \\
\hline \multirow{2}{*}{ Dissemination willingness (DW) } & DW 2 & 0.855 & & & \\
\hline & DW 3 & 0.783 & & & \\
\hline \multirow[t]{3}{*}{ Adult attachment (AA) } & AA 1 & 0.852 & 0.792 & 0.877 & 0.703 \\
\hline & AA 2 & 0.820 & & & \\
\hline & AA 3 & 0.844 & & & \\
\hline \multirow[t]{2}{*}{ Social motivation (SM) } & SM 1 & 0.844 & 0.622 & 0.841 & 0.726 \\
\hline & SM 2 & 0.860 & & & \\
\hline \multirow[t]{2}{*}{ Risk perception (RP) } & RP 1 & 0.878 & 0.707 & 0.872 & 0.773 \\
\hline & RP 2 & 0.881 & & & \\
\hline
\end{tabular}


TABLE 3 | Validity analysis.

\begin{tabular}{|c|c|c|c|c|c|c|c|}
\hline & DW & ADI & EM & AA & SM & CSP & $\mathbf{R P}$ \\
\hline Dissemination willingness & 0.831 & & & & & & \\
\hline Affective disposition of information & 0.121 & 0.867 & & & & & \\
\hline Emotional motivation & 0.199 & 0.418 & 0.858 & & & & \\
\hline Adult attachment & 0.036 & 0.360 & 0.405 & 0.839 & & & \\
\hline Social motivation & 0.309 & 0.019 & 0.078 & -0.005 & 0.852 & & \\
\hline
\end{tabular}

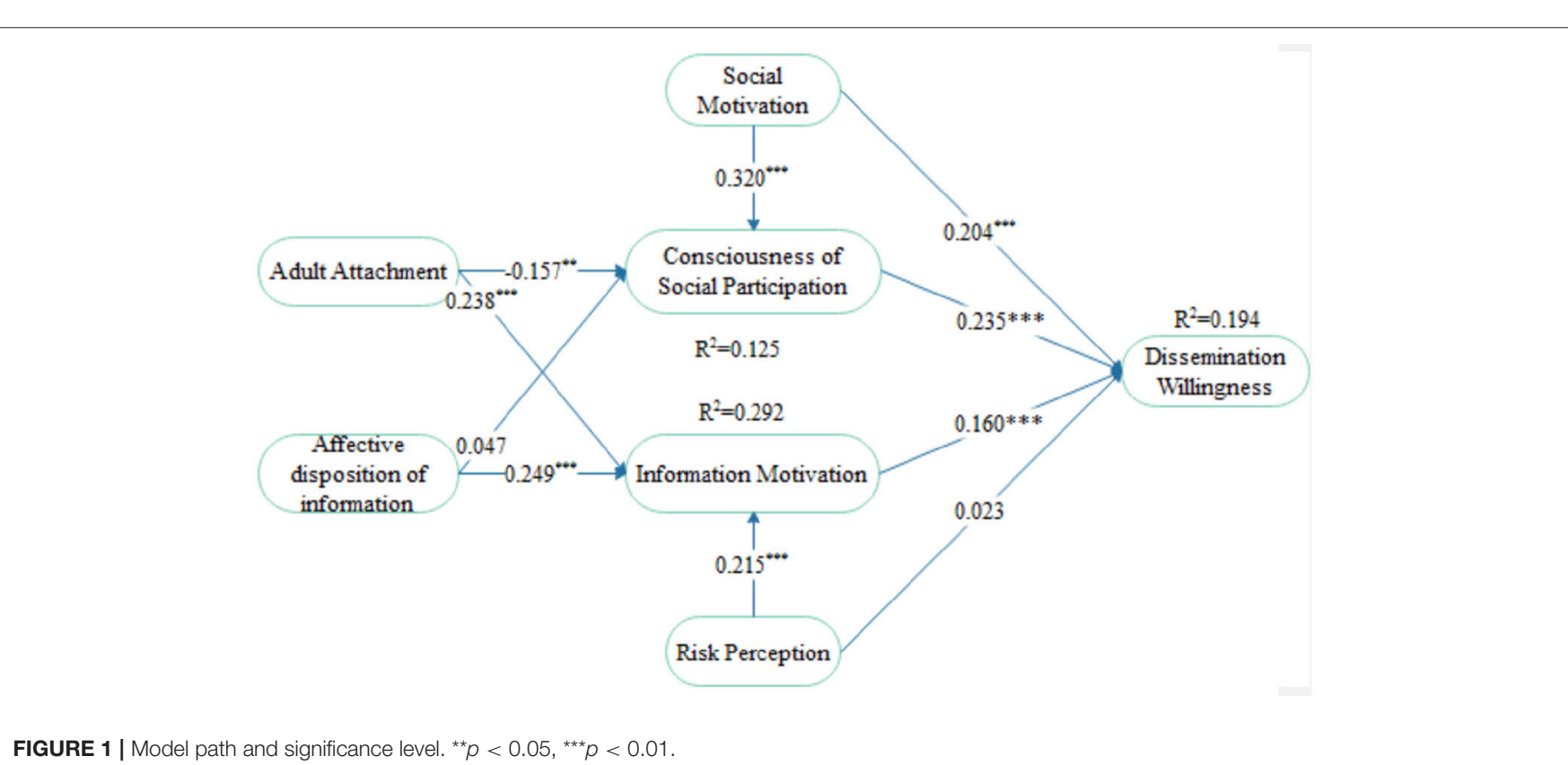

FIGURE 1 | Model path and significance level. ${ }^{* *} p<0.05,{ }^{* \star *} p<0.01$.

to all variables was greater than the threshold value of 0.7 , thereby indicating a good construct validity of the scale (69).

The average variance extracted (AVE) of each variable is more than 0.65 , thereby indicating that the convergence validity of the table is good (70). Table 3 illustrates that the square root of AVE of each variable to be more than the correlation coefficient of this variable vis-à-vis other variables. A good discriminant validity exists amongst the variables (71). In summary, the scales used in this study have good validity.

\section{DATA ANALYSIS AND RESULTS}

The Partial Least Squares (PLS) method has been deployed for analyzing the study data. PLS is a new multivariate data analytical method. Compared to other methods, PLS is more reliable and stable in the calculation, making it suitable for the analysis on small sample data. Importantly, PLS can achieve simultaneous modeling and prediction and realize the comprehensive simplification of the multivariable system and the correlation analysis between the two groups of variables, which can effectively solve the collinearity problem.
The main purpose of PLS is to construct the regression models of multiple dependent and independent variables. PLS can flexibly set the types of external relations in the structural equation whilst constructing the model according to the actual situation, that is, supporting constitutive and reflective models. Here, the research model is analyzed via the Smart PLS3.0 software.

\section{Structural Model Test}

Path coefficient represents the strength of the relationship between independent and dependent variable. The analytical results of the path coefficient for the research model being validated are shown in Figure 1 and Table 4.

From the analysis results, among the first ten (10) primary hypotheses advanced on the structural model test, eight (8) were supported. $\mathrm{R}^{2}$ represents the variance variability of the dependent variable explained by the independent variable. In this study, bootstrapping repeated sampling method is used to calculate the $t$-value of the significance test based on the selection of 2,000 samples. The degree of interpretation of consciousness of social participation, EM and dissemination willingness are $0.426,0.427$, 
TABLE 4 | Hypothesis test results.

\begin{tabular}{|c|c|c|c|c|c|}
\hline Hypothesis & Path & Means & SD & $t$-Value & $P$ \\
\hline $\mathrm{H} 1$ & $\mathrm{AA} \rightarrow \mathrm{CSP}$ & -0.160 & 0.063 & 2.483 & 0.013 \\
\hline $\mathrm{H} 2$ & $\mathrm{SM} \rightarrow \mathrm{CSP}$ & 0.324 & 0.051 & 6.323 & 0.000 \\
\hline H3 & $\mathrm{ADI} \rightarrow \mathrm{CSP}$ & 0.048 & 0.060 & 0.774 & 0.439 \\
\hline $\mathrm{H} 4$ & $\mathrm{ADI} \rightarrow \mathrm{EM}$ & 0.293 & 0.057 & 5.114 & 0.000 \\
\hline H5 & $\mathrm{AA} \rightarrow \mathrm{EM}$ & 0.241 & 0.057 & 4.182 & 0.000 \\
\hline H6 & $\mathrm{RP} \rightarrow \mathrm{EM}$ & 0.218 & 0.058 & 3.678 & 0.000 \\
\hline $\mathrm{H} 7$ & $\mathrm{SM} \rightarrow \mathrm{DW}$ & 0.205 & 0.056 & 3.636 & 0.000 \\
\hline H8 & $\mathrm{CSP} \rightarrow \mathrm{DW}$ & 0.240 & 0.060 & 3.890 & 0.000 \\
\hline H9 & $\mathrm{EM} \rightarrow \mathrm{DW}$ & 0.159 & 0.054 & 2.967 & 0.003 \\
\hline $\mathrm{H} 10$ & $\mathrm{RP} \rightarrow \mathrm{DW}$ & 0.024 & 0.055 & 0.409 & 0.683 \\
\hline
\end{tabular}

and 0.545 respectively, thereby indicating that the model has a good interpretation effect (71).

As quantified in Table 4, bootstrapping method has been used to test the significance of the path coefficient of the structural model. As depicted in the distribution plot of hypothesis testing shown in Figure 2, there is a significant correlation between the seven variables in the hypothesis test.

First, AA (adult attachment) has a significantly positive influence on the consciousness of social participation ( $\beta$ $=0.157, t=2.438$ ), affirming Hypothesis H1. SM (social motivation) also has shown a significantly positive influence on the consciousness of social participation $(\beta=0.320, t=$ 6.323), confirming Hypothesis H2. Conversely, IAD (information affective disposition) has no significant positive effect on the consciousness of social participation $(\beta=0.047, t=0.774)$, inferring that Hypothesis $\mathrm{H} 3$ is not supported.

Even so, for hypotheses $\mathrm{H} 4$ through $\mathrm{H6}$, AD has shown to have a significant positive influence on EM (emotional motivation) ( $\beta=0.249, t=5.114$ ); hence, Hypothesis $H 4$ is supported. AA also has a significant positive influence on $\operatorname{EM}(\beta=0.238, t=$ 4.182), confirming Hypothesis H5. As well, risk perception has a significant positive influence on $\operatorname{EM}(\beta=0.215, t=3.678)$, thereby confirming Hypothesis H6.

In term of hypotheses $H 7$ through $H 10$, results of the data analysis showed that SM also has a significant positive influence on the dissemination willingness $(\beta=0.204, t=$ 3.636). Therefore, Hypothesis $H 7$ is supported. As well, the consciousness of social participation has a significant positive influence on dissemination willingness $(\beta=0.235, t=3.890)$. Hence, Hypothesis $H 8$ is also supported. Additionally, EM has a significant positive influence on dissemination willingness $(\beta=$ $0.160, t=2.967$ ), thereby confirming Hypothesis H9. However, risk perception has no significant influence on dissemination willingness ( $\beta=0.023, t=0.409$ ). As such, Hypothesis H10 is not supported.

\section{Mediating Effect Test}

In this study, we conducted a mediating effect hypothesis test by using a three-step mediating regression analysis as proposed by (72). In the first step, $\mathrm{AD}$ is used to regress dissemination willingness; next, $\mathrm{AD}$ is used to regress EM. Finally, in the

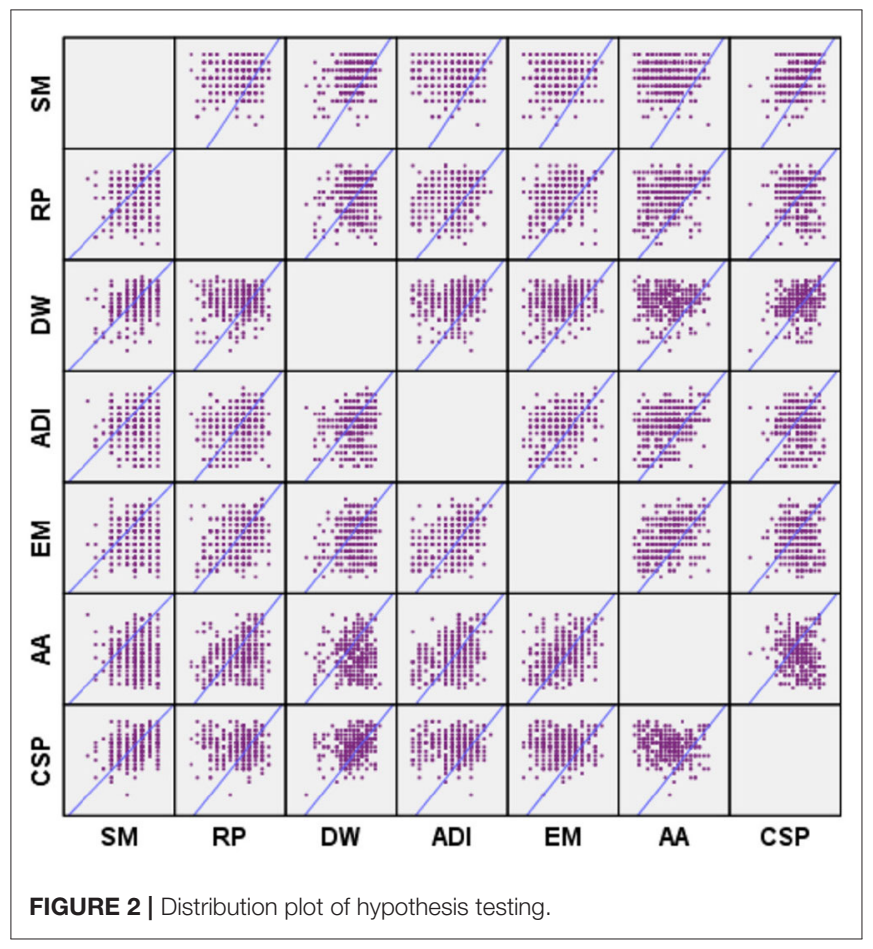

third step, $\mathrm{AD}$ and $\mathrm{EM}$ were used together to regress the dependent variable (dissemination willingness). The regression coefficient must be significant in the first and second steps. In the third step, if the regression coefficient of EM is significant, and the regression coefficient of the independent variable $\mathrm{AD}$ is insignificant, then EM plays a complete mediating role. If the regression coefficients of $\mathrm{AD}$ and $\mathrm{EM}$ are significant, but the regression coefficient of $\mathrm{AD}$ becomes weak, then $\mathrm{EM}$ plays a partial mediating role.

This study analyses the mediating role of EM in the relationship between $\mathrm{AD}$ and dissemination willingness via the bootstrapping method on the basis of the suggestions of (73). Here, 5,000 times of repeated sampling is adopted in the bootstrap analysis to construct a $95 \%$ confidence interval for bias correction. 
Table 5 demonstrates that the indirect effect of EM in the relationship between $\mathrm{AD}$ and dissemination willingness is $0.051(\mathrm{CI}=[0.014,0.088])$, and its bootstrap 95\% confidence interval does not include zero. This result indicates that the mediating effect of EM between $\mathrm{AD}$ and dissemination willingness is significant. Therefore, hypothesis H11 is supported. The indirect effect of the consciousness of social participation in the relationship between SM and dissemination willingness is $0.070(\mathrm{CI}=[0.038,0.127])$, and its bootstrap 95\% confidence interval does not include zero. This result indicates also that the mediating effect of the consciousness of social participation in the relationship between social motivation and dissemination willingness is significant. Hypothesis H12 is confirmed.

\section{Moderating Effect Test}

First, the centralization treatment is conducted for the independent and moderating variables to test the regulatory effect of SM on the relationship between risk perception and dissemination willingness. Then, the product terms of SM, risk perception and dissemination willingness are constructed to conduct a multilevel regression analysis. SM has a significant moderating effect on the relationship between risk perception and dissemination willingness.

In the study, risk perception is divided into high, medium, and low situations to clearly show the role of the moderating variables. Excel is used to draw the influence of SM on dissemination willingness in high, medium, and low risk perception. The main effect is 0.87 ; the moderating variable effect is 0.724 ; and the moderating effect is -0.121 . The moderating effects are shown in Figure 3. Our results show that the influence of SM on dissemination willingness is reduced when the risk perception is high, confirming Hypothesis H13.

\section{DISCUSSION}

AA and SM have significant positive effects on the consciousness of social participation, Hypothesis H1and H2 are demonstrated. Nonetheless, the positive influence of $\mathrm{AD}$ on the consciousness of social participation is not confirmed as Hypothesis $\mathrm{H} 3$ is not supported. This situation is likely (and primarily) due to college students being in the period of psycho-physio development with the lack of rational judgment on the development of social affairs. Hence, their ability to judge the reliability and certainty of information to effectively strengthen the education of epidemic-related knowledge should be reinforced to make them understand better the epidemic situation based on a rational and scientific approach. Adopting such an evidence-based strategy, college students will then be aided to adopt positive coping styles and maintain physical and mental health.

$\mathrm{SM}$, the consciousness of social participation and EM have significant positive effects on dissemination willingness. Hypothesis H7, H8, $\mathrm{H} 9$ have been demonstrated. Nonetheless, the positive influence of risk perception on dissemination willingness is not confirmed as Hypothesis 10 is not affirmed. Additionally, this analysis indicates the varying characteristics of college students. The self-health level of people and the psychological processing mode of external emergencies are uniquely different
(74). This situation will lead to varying risk perception on crisis events, thereby resulting in different coping methods. College students should have a theory-based understanding on their own physical health level and objective knowledge of their own psychological processing mode. These students should formulate a specific epidemic response mode based on their specific actual situations to alleviate the worries and anxiety caused by the epidemic.

$\mathrm{AD}, \mathrm{AA}$, and risk perception have significant positive effects on EM. Hypothesis H4, H5, H6 have been demonstrated. Public opinion is generated around intermediary social events (75). Hence, college students' preference for events can directly affect their behaviors of expressing their opinions, ideas, or emotions. However, affective disposition and risk perception are always the decisive factors to attract college students' attention.

EM plays a mediating role in the relationship between $\mathrm{AD}$ and dissemination willingness. Hypothesis $H 11$ has been demonstrated. College students will be worried and panic about the spread of the epidemic (76), and they will also show a concerning attitude toward the government's measures to prevent and control the epidemic, which will affect dissemination willingness. The consciousness of social participation plays a mediating role in the relationship between SM and dissemination willingness. Hypothesis $\mathrm{H} 12$ has been demonstrated. This result is obtained as college students have a strong sense of participation in social activities. Students hope to help their friends and relatives understand the extent and severity of the epidemic spread via the dissemination of public opinion information. The consciousness of social participation has a mediating effect on dissemination willingness. SM moderates the relationship between risk perception and dissemination willingness. Hypothesis $\mathrm{H} 13$ has been demonstrated.

COVID-19 is characterized by rapid spread, high infection, and wide spreading scope. College students have a deep understanding on the risk of epidemic development and hope to help their friends, classmates, and family members through their own efforts. SM has a great effect on the relationship between risk perception and dissemination willingness.

\section{IMPLICATIONS}

In this study, we have constructed a research explanatory model on the spread of major epidemic IPO and proposed the coping strategies. These initiatives can provide reference and insight into the current and future IPO governance practice in major epidemic situation.

More importantly, these initiatives provide theory-based thinking for further enriching and deepening the research on IPO governance with major epidemic as the typical sudden public health practice.

\section{Theoretical Implications}

This study unveils key influencing factors on IPO dissemination in major epidemic prevention and control from two primary dimensions, namely, SM and EM. The conclusion of this study compensates for the current studies on group factors and the mechanism of social participation consciousness. 
TABLE 5 | Mediating effect of emotional motivation and consciousness of social participation.

\begin{tabular}{|c|c|c|c|c|}
\hline \multirow[t]{2}{*}{ Indirect effect } & \multirow[t]{2}{*}{ Estimated value } & \multicolumn{2}{|c|}{$97.5 \% \mathrm{Cl}$} & \multirow[t]{2}{*}{ Conclusion } \\
\hline & & Lower & Upper & \\
\hline Affective disposition of information $\rightarrow$ emotional motivation $\rightarrow$ dissemination willingness & 0.051 & 0.014 & 0.088 & Mediation eff \\
\hline Social motivation $\rightarrow$ consciousness of social participation $\rightarrow$ dissemination willingness & 0.070 & 0.038 & 0.127 & Mediation ef \\
\hline
\end{tabular}

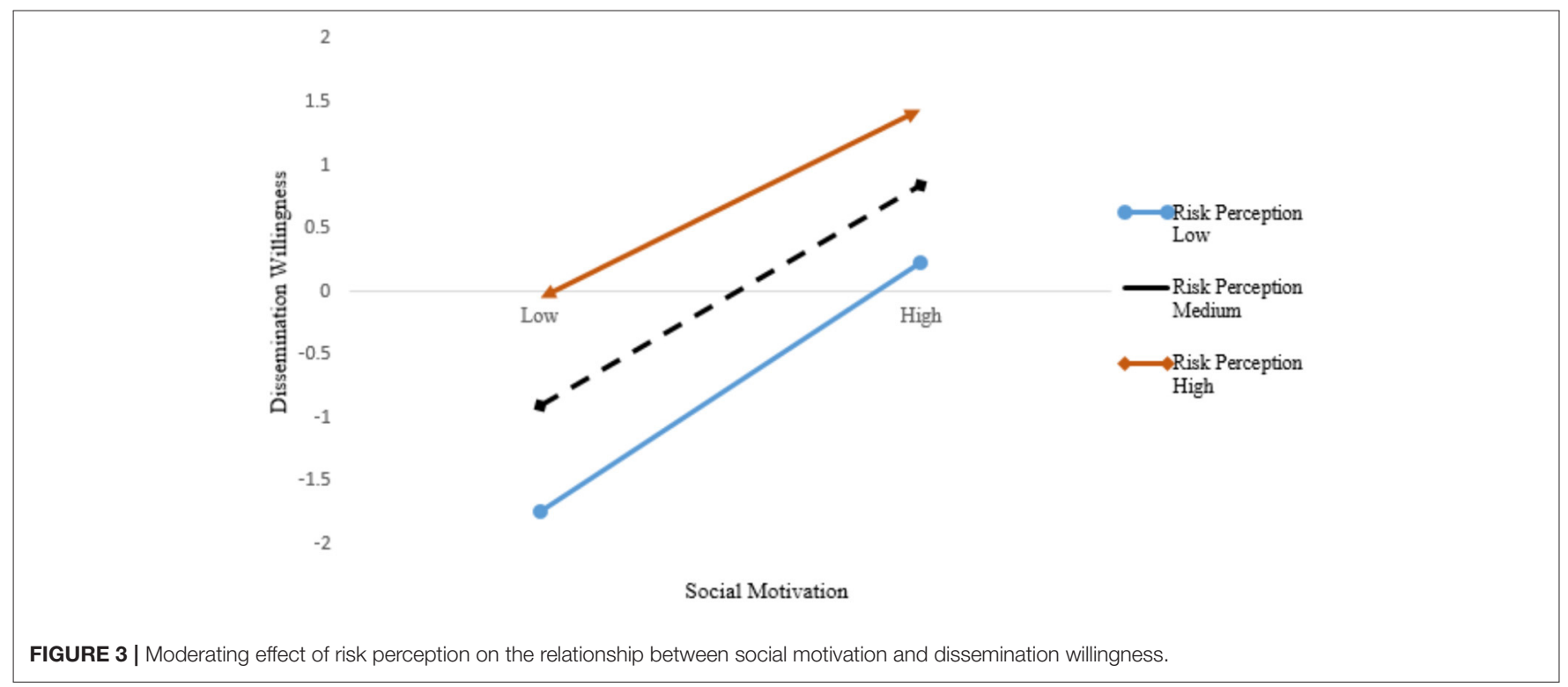

This study enriches IPO research with several theoretical insights, expanding the research scope of students' information behavior theory in the process of spreading public opinion on the epidemic.

Studies have theoretically verified that EM plays a mediating role in the relationship between $\mathrm{AD}$ and dissemination willingness; consciousness of social participation plays a mediating role in the relationship between SM and dissemination willingness; and SM moderates the relationship between risk perception and dissemination willingness (77). The research model offers insight and analysis on the governance mechanism of IPO in the prevention and control of major epidemic to supplement the understanding of current studies on the role of governance mechanism.

\section{Managerial Implications}

The governance effect of IPO determines the guidance of public opinion in the context of sudden events, which is directly related to social stability. Effective measures for IPO governance must be determined.

The outcome of this effort is of great relevance to the governance of IPO in the prevention and control of major epidemic and of applicable significance to advancing the government's information governance ability. We should strengthen the guidance of public opinion in major epidemic prevention and control and fully build and make good use of all types of information transmission paths. The spread of IPO is a group activity, rather than an individual action. This situation has a strong external effect.

In the context of public emergencies, IPO has an inciting force to the group. When dealing with the IPO in major epidemic prevention and control, it also tests the ability of prevention and response to group events. We must set up a network warning in advance, implement information communication channels in time and ensure the real-time interaction of information. These steps can reduce the possibility of Internet users to believe and spread rumors to a certain extent, thereby promoting the public to form self-awareness and moral obligations and maintain a harmonious network environment.

\section{LIMITATIONS AND FUTURE RESEARCH}

In this study, several key limitations may be observed. First, the study is based on the risk of spreading COVID-19 and users' risk perception. Users' habits and preference of public opinion dissemination, the characteristics of subjects and objects of spreading public opinion and other influencing factors have not been included in this study.

Importantly, the model established here is just a preliminary prototype, and its prediction accuracy may still need enhancement. After further improvement of the measurement scheme and simulation means, the relevance and applicability of the studied model will be greatly improved. As well, given that the objects investigated are college 
students, restrictions on age and educational level may exist. In the future, we anticipate broadening the selection of the research objects and comprehensively consider the differences amongst groups of different regions, occupations, and ages.

Finally, public opinion dissemination in an era of major epidemic prevention and control will also be intervened by related government and health departments; for example, the spread of proper health knowledge, criticism, and education to fight malicious rumor makers via appropriate social media channels by relevant authorities may improve the dissemination of public opinion. In addition to the sources, objects and contents of dissemination, the thirdparty intervention can and should be further studied in the future.

\section{DATA AVAILABILITY STATEMENT}

The raw data supporting the conclusions of this article will be made available by the authors, without undue reservation.

\section{REFERENCES}

1. Yun GW, Morin D, Park S, Joa CY, Labbe B, Lim J, et al. Social media and flu: Media Twitter accounts as agenda setters. Int J Med Inform. (2016) 91:67-73. doi: 10.1016/j.ijmedinf.2016.04.009

2. Hunt A, Matthew G. Social media and fake news in the (2016). J Econ Perspect. (2017) 31:211-36. doi: 10.1257/jep.31.2.211

3. Zhang Z, Bors G. "Less is more": Mining useful features from Twitter user profiles for Twitter user classification in the public health domain. Online Inf Rev. (2019) 44:213-37. doi: 10.1108/ OIR-05-2019-0143

4. Chua AYK, Banerjee S. To share or not to share: The role of epistemic belief in online health rumors. Int J Med Inform. (2017) 108:3641. doi: 10.1016/j.ijmedinf.2017.08.010

5. Bao Y, Sun Y, Meng S, Shi J, Lu L. 2019-nCoV epidemic: address mental health care to empower society. Lancet. (2020) 395:e37-8. doi: 10.1016/S0140-6736(20)30309-3

6. Ghosh S. Predictive model with analysis of the initial spread of COVID-19 in India. Int J Med Inform. (2020) 143:104262. doi: 10.1016/ j.ijmedinf.2020.104262

7. Milenkovic A, Jankovic D, Rajkovic P. Extensions and adaptations of existing medical information system in order to reduce social contacts during COVID-19 pandemic. Int J Med Inform. (2020) 141:104224. doi: 10.1016/ j.ijmedinf.2020.104224

8. Ozili P. COVID-19 in Africa: socio-economic impact, policy response and opportunities. Int J Sociol Soc Policy. (2020). doi: 10.1108/IJSSP-05-2020-0171 [Epub ahead of print].

9. Sharma S, Bhatta J. Public health challenges during the COVID-19 outbreak in Nepal: a commentary. J Health Res. (2020) 34:373-6. doi: 10.1108/ JHR-05-2020-0124

10. Kumar PS, Priyabrata C, A. production recovery plan in manufacturing supply chains for a high-demand item during COVID-19. Int J Phys Distrib Logist Manag. (2020). 51:104-25.

11. Tang $\mathrm{W}, \mathrm{Hu} \mathrm{T}$, Yang $\mathrm{L}$, $\mathrm{Xu}$ J. The role of alexithymia in the mental health problems of home-quarantined university students during the COVID-19 pandemic in China. Pers Individ Dif. (2020) 165:11031. doi: 10.1016/j.paid.2020.110131

12. Nguyen DV, Pham GH, Nguyen DN. Impact of the Covid-19 pandemic on perceptions and behaviors of university students in Vietnam. Data in Brief. (2020) 31:105880. doi: 10.1016/ j.dib.2020.105880

\section{ETHICS STATEMENT}

The studies involving human participants were reviewed and approved by Wuhan Business University Ethics Committee. The patients/participants provided their written informed consent to participate in this study.

\section{AUTHOR CONTRIBUTIONS}

Overall supervision, advisor, and final approval of submitted work by LL. Primary research data and statistical analytic work by PY. Review of research and final submission by JT. All authors contributed to the article and approved the submitted version.

\section{FUNDING}

This work was supported by the Hubei Social Science Research Fund [19ZD074].

13. Ge W, Xiao Y, Xing B, Shen M. Miao Q. The relationship between college students' cogniton of the COVID-19 China. J Sch Health. (2020) 41:670-2. doi: 10.16835/j.cnki.1000-9817.2020.05.010

14. Liu M, Li T, Liu N. Investigation and analysis of college students' cognition, attitude and behavior of new coronavirus infected pneumonia. Chinese Gen Pract. (2020) 18:938-40. doi: 10.12104/j.issn.1674-4748.2020.08.064

15. Tang W, Hu T, Hu B, Jin C, Wang G, Xie C, et al. Prevalence and correlates of PTSD and depressive symptoms one month after the outbreak of the COVID19 epidemic in a sample of home-quarantined Chinese university students. $J$ Affect Disord. (2020) 274:1-7. doi: 10.1016/j.jad.2020.05.009

16. Odriozola-González P, Planchuelo-Gómez Á, Irurtia MJ, de Luis-García R. Psychological effects of the COVID-19 outbreak and lockdown among students and workers of a Spanish university. Psychiatry Res. (2020) 290:10513. doi: 10.1016/j.psychres.2020.113108

17. Kaparounaki CK, Patsali ME, Mousa D-PV, Papadopoulou EVK, Papadopoulou KKK, Fountoulakis KN. University students' mental health amidst the COVID-19 quarantine in Greece. Psychiatry Res. (2020) 290:111-3. doi: 10.1016/j.psychres.2020.113111

18. Saefi M, Fauzi A, Kristiana E, Adi WC, Muchson M, Setiawan ME, et al. Survey data of COVID-19-related knowledge, attitude, and practices among indonesian undergraduate students. Data in Brief. (2020) 31:110. doi: 10.1016/j.dib.2020.105855

19. Yu Y, Yu Y, Li B. Effects of mindfulness and meaning in life on psychological distress in Chinese university students during the COVID19 epidemic: A chained mediation model. Asian J Psychiatr. (2020) 53:102211. doi: 10.1016/j.ajp.2020.102211

20. Wright KP, Linton SK, Withrow D, Casiraghi L, Lanza SM, Iglesia Hdl, Vetter C, Depner CM. Sleep in university students prior to and during COVID-19 stay-at-home orders. Curr Biol. (2020). doi: 10.1016/j.cub.2020.06.022

21. Guadix SW, Winston GM, Chae JK, Haghdel A, Chen J, Younus I, et al. Medical student concerns relating to neurosurgery education during COVID19. World Neurosurg. (2020). doi: 10.1016/j.wneu.2020.05.090

22. Wang Z-H, Yang H-L, Yang Y-Q, Liu D, Li Z-H, Zhang X-R, et al. Prevalence of anxiety and depression symptom, and the demands for psychological knowledge and interventions in college students during COVID-19 epidemic: a large cross-sectional study. J Affect Disord. (2020). doi: 10.1016/j.jad.2020.06.034

23. Liu S, Liu Y, Liu Y. Somatic symptoms and concern regarding COVID19 among Chinese college and primary school students: A crosssectional survey. Psychiatry Res. (2020) 289:1-5. doi: 10.1016/j.psychres.2020. 113070 
24. Kapasia N, Paul P, Roy A, Saha J, Zaveri A, Mallick R, et al. Impact of lockdown on learning status of undergraduate and postgraduate students during COVID-19 pandemic in West Bengal, India. Child Youth Serv Rev. (2020) 116:105194. doi: 10.1016/j.childyouth.2020. 105194

25. Rzymski P, Nowicki M. COVID-19-related prejudice toward Asian medical students: A consequence of SARS-CoV-2 fears in Poland. I Infect Public Health. (2020) 13:873-6. doi: 10.1016/j.jiph.2020.04.013

26. Cao W, Fang Z, Hou G, Han M, Xu X, Dong J, et al. The psychological impact of the COVID-19 epidemic on college students in China. Psychiatry Res. (2020) 287:112934. doi: 10.1016/j.psychres.2020. 112934

27. Drissi N, Ouhbi S, Janati Idrissi MA, Ghogho M. An analysis on self-management and treatment-related functionality and characteristics of highly rated anxiety apps. Int J Med Inform. (2020) 141:104243. doi: 10.1016/j.ijmedinf.2020.104243

28. Savitsky B, Findling Y, Ereli A, Hendel T. Anxiety and coping strategies among nursing students during the covid-19 pandemic. Nurse Educ Pract. (2020). doi: 10.1016/j.nepr.2020.102809

29. Zhang Q, He Y-J, Zhu Y-H, Dai M-C, Pan M-M, Wu J-Q, et al. The evaluation of online course of Traditional Chinese Medicine for MBBS international students during the COVID-19 epidemic period. Integrative Medicine Research. (2020) 9:100449. doi: 10.1016/j.imr.2020. 100449

30. Wang S, Song Y. Chinese online public opinions on the two-child policy. Online Information Review. (2019) 43:387403. doi: 10.1108/OIR-07-2017-0217

31. Cheng X, Wang C. Characteristics, causes and guidance of network public opinion crisis. People's Tribune. (2014) 20:133-5.

32. Shan S, Liu M, Xu X. Analysis of the key influencing factors of haze information dissemination behavior and motivation in WeChat. Inf Discov Deliv. (2017) 45:21-9. doi: 10.1108/IDD-09-2016-0029

33. Yang Y, Xie X. Configuration analysis of influencing factors of internet public opinion based on QCA. J Intelligence. (2019) 38:142-6.

34. Thelwall M. Blog searching: The first general-purpose source of retrospective public opinion in the social sciences? Online Inf Rev. (2007) 31:27789. doi: 10.1108/14684520710764069

35. Lu J. Public emergency network public opinion collection and evaluation strategy. Journalism Lover. (2019) 6:59-61.

36. Wang X, Zhao D, Yang M, Duan L, Xiang Meng M, Guo Q. Public opinion dissemination on mobile internet- a case of Ebola. Inf Discov Deliv. (2017) 45:87-100. doi: 10.1108/IDD-02-2017-0013

37. Li J, Xie Y. Research on the influencing factors of the heat of online public opinion:an empirical analysis based on 10,600 events from 20102018. Journalism and Mass Communication Monthly. (2020) 2:40-8. doi: 10.15897/j.cnki.cn51-1046/g2.20200221.006

38. Yu L, Li L, Tang L, Dai W, Hanachi C, A. multi-agent-based online opinion dissemination model for China's crisis information release policy during hazardous chemical leakage emergencies into rivers. Online Inf Rev. (2017) 41:537-57. doi: 10.1108/OIR-04-2015-0126

39. Yang Y, Wang J. The evolution of emergency network public opinion influenced by emotional factors. Informat Sci. (2020) 38:35-41.

40. Salter A, Fox RJ, Tyry T, Cutter G, Marrie RA. The association of fatigue and social participation in multiple sclerosis as assessed using two different instruments. Mult Scler Relat Disord. (2019) 31:16572. doi: 10.1016/j.msard.2019.04.014

41. Zhu AYF, Chan ALS, Chou KL. Creative social media use and political participation in young people: The moderation and mediation role of online political expression. J Adolesc. (2019) 77:108-17. doi: 10.1016/j.adolescence.2019.10.010

42. Shu $\mathrm{C}, \mathrm{Hu} \mathrm{N}$, Zhang $\mathrm{X}, \mathrm{Ma} \mathrm{Y}$, Chen X. Adult attachment and profile images on Chinese social networking sites: A comparative analysis of Sina Weibo and WeChat. Comput Human Behav. (2017) 77:26673. doi: 10.1016/j.chb.2017.09.014

43. Hilvert-Bruce Z, Neill JT, Sjöblom M, Hamari J. Social motivations of live-streaming viewer engagement on Twitch. Comput Human Behav. (2018) 84:58-67. doi: 10.1016/j.chb.2018. 02.013
44. Hernandez B, Montaner T, Sese FJ, Urquizu P. The role of social motivations in e-learning: How do they affect usage and success of ICT interactive tools? Comput Human Behav. (2011) 27:2224-32. doi: 10.1016/j.chb.2011.07.001

45. Guha M. The encyclopaedic dictionary of psychology. Reference Reviews. (2007) 21:12-4. doi: 10.1108/09504120710719419

46. Zhang Y, Liu Y, Li W, Peng L, Yuan C, A. study of the influencing factors of mobile social media fatigue behavior based on the grounded theory. Inf Discov Deliv. (2020) 48:91-102. doi: 10.1108/IDD-11-2019-0084

47. Li Y, Wu R, Li D. The influence of subjective characteristics of social network sites on consumers' word-of-mouth sharing. Online Inf Rev. (2020) 44:97794. doi: 10.1108/OIR-09-2018-0263

48. Lund R. Researching crisis-Recognizing the unsettling experience of emotions. Emotion Space \& Society. (2012) 5:94-102. doi: 10.1016/j.emospa.2010.09.003

49. Ravaja N, Korhonen P, Köksalan M, Lipsanen J, Salminen M, Somervuori O, Wallenius J. Emotional-motivational responses predicting choices: The role of asymmetrical frontal cortical activity. J Eco Psychol. (2016). 52:5670. doi: 10.1016/j.joep.2015.11.007

50. Hotle S, Murray-Tuite P, Singh K. Influenza risk perception and travelrelated health protection behavior in the US: Insights for the aftermath of the COVID-19 outbreak. Transp Res Interdiscip Perspect. (2020) 5:100127. doi: 10.1016/j.trip.2020.100127

51. Zhang 1, Wei j, Boncella Robert J. Emotional communication analysis of emergency microblog based on the evolution life cycle of public opinion. Inf Discov Deliv. (2020). 48:151-63. doi: 10.1108/IDD-10-2019-0074

52. Lee CS, Ma L. News sharing in social media: The effect of gratifications and prior experience. Comput Human Behav. (2012) 28:331-9. doi: 10.1016/j.chb.2011.10.002

53. Stuart JB, Martin B. Modeling use continuance behavior in microblogging services: the case of Twitter. Data Processor for Better Business Education. (2011) 51:1-10. doi: 10.1080/08874417.2011.11645496

54. Weingart LR, Brett JM, Olekalns M, Smith PL. Conflicting social motives in negotiating groups. J Pers Soc Psychol. (2007) 93:9941010. doi: 10.1037/0022-3514.93.6.994

55. Cao Y, Shao P, Zhu W. Research on Internet of information propagation in enterprise microblogging based on public platform. Chin J Informat Syst. (2013) 11:64-76.

56. Dhagarra D, Goswami M, Kumar G. Impact of trust and privacy concerns on technology acceptance in healthcare: an indian perspective. Int J Med Inform. (2020) 141:104164. doi: 10.1016/j.ijmedinf.2020.104164

57. Hsu CL, Lin CC. Acceptance of blog usage: The roles of technology acceptance, social influence and knowledge sharing motivation. Informat Management. (2008) 45:65-74. doi: 10.1016/j.im.2007.11.001

58. Park N, Oh HS, Kang N. Factors influencing intention to upload content on Wikipedia in South Korea: The effects of social norms and individual differences. Comput Human Behav. (2012) 28:898-905. doi: 10.1016/j.chb.2011.12.010

59. Fennelly O, Cunningham C, Grogan L, Cronin H, O'Shea C, Roche M, Lawlor F, O’Hare N. Successfully implementing a national electronic health record: a rapid umbrella review. Int J Med Inform. (2020). 104281. doi: 10.1016/j.ijmedinf.2020.104281

60. He T, Huang C, Li M, Zhou Y, Li S. Social participation of the elderly in China: The roles of conventional media, digital access and social media engagement. Telemat Informat. (2020) 48:101347. doi: 10.1016/j.tele.2020. 101347

61. Xu W, Liu L, Shang W. Leveraging cross-media analytics to detect events and mine opinions for emergency management. Online Inf Rev. (2017) 41:487506. doi: 10.1108/OIR-08-2015-0286

62. Xie Y, Qiao R, Shao G, Chen H. Research on Chinese social media users' communication behaviors during public emergency events. Telemat Inform. (2017) 34:740-54. doi: 10.1016/j.tele.2016.05.023

63. Zhang Y, Wang L, Duan Y. Agricultural information dissemination using ICTs: A review and analysis of information dissemination models in China. Inf Process Agric. (2016) 3:17-29. doi: 10.1016/j.inpa.2015. 11.002

64. Richins ML. Measuring Emotions in the Consumption Experience | Journal of Consumer Research | Oxford Academic. J Consum Res. (1997) 24:12746. doi: 10.1086/209499 
65. Bo S. The Influencing Factors of Public Crisis Information Dissemination Behavior under Mobile Internet Environment. J Intell. (2013) 32:14-8.

66. Brennan KA, Clark CL, Shaver PR. Self-report measurement of adult attachment: An integrative overview. Simpson J, Rholes W, editors. New York, NY: Guilford. (1998). p. 46-76.

67. Zhao J, Cheng J. Empirical research of users' willingness to propagate microblogging public opinion based on perceptions, preferences, and involvements. J Chin Soc Scient Technical Informat. (2014) 33:416-25.

68. Yang J, Sarathy R, Lee J. The effect of product review balance and volume on online Shoppers' risk perception and purchase intention. Decis Support Syst. (2016) 89:66-76. doi: 10.1016/j.dss.2016.06.009

69. Nunnally.J. Psychometric Theory. New York, NY: McGraw-Hill. (1978).

70. Fornell C, Larcker DF. Evaluating structural equation models with unobservable variables and measurement err. J Market Res. (1981) 18:3950. doi: 10.1177/002224378101800313

71. Hair JF, Anderson RE, Tatham RL, Black WC. Multivariate Data Analysis. Vol 5th edn New Jersey: Prentice Hall. (1998).

72. Baron RM, Kenny DA. The moderator-mediator variable distinction in social psychological research:Conceptual,strategic, and statistical considerations. J Pers Soc Psychol. (1986) 51:1173-82. doi: 10.1037/0022-3514.51. 6.1173

73. Edwards JR, Lambert LS. Methods for integrating moderation and mediation: A general analytical framework using moderated path analysis. Psychol Methods. (2007) 12:1-22. doi: 10.1037/1082-989X.12.1.1

74. Liu Z. Scholarly communication in educational psychology: a journal citation analysis. Collection Building. (2007) 26:1128. doi: 10.1108/01604950710831915
75. Pilar García-Guadilla M, Blauert J. Environmental Social Movements in Latin America and Europe: Challenging Development and Democracy. Int J Sociol Soc Policy. (1992) 12:1-274. doi: 10.1108/eb060146

76. Hirsch EL. Sacrifice for the Cause: Group Processes, Recruitment, and Commitment in a Student Social Movement. Am Sociol Rev. (1990) 55:243. doi: $10.2307 / 2095630$

77. Zhang Z, Chen H, Xiao B. Understanding eWOM of Chinese Governments information service: a perceived value-based perspective. Inf Discov Deliv. (2019) 47:251-8. doi: 10.1108/IDD-08-2019-0058

Conflict of Interest: The authors declare that the research was conducted in the absence of any commercial or financial relationships that could be construed as a potential conflict of interest.

Publisher's Note: All claims expressed in this article are solely those of the authors and do not necessarily represent those of their affiliated organizations, or those of the publisher, the editors and the reviewers. Any product that may be evaluated in this article, or claim that may be made by its manufacturer, is not guaranteed or endorsed by the publisher.

Copyright (c) 2022 Ye, Liu and Tan. This is an open-access article distributed under the terms of the Creative Commons Attribution License (CC BY). The use, distribution or reproduction in other forums is permitted, provided the original author(s) and the copyright owner(s) are credited and that the original publication in this journal is cited, in accordance with accepted academic practice. No use, distribution or reproduction is permitted which does not comply with these terms. 


\section{APPENDIX: CONSTRUCTS AND ITEMS}

\section{Affective Disposition (AD) of Information}

The information on the epidemic situation clearly expresses the questioning attitude to the government's prevention and control measures.

The information on the epidemic situation reveals dissatisfaction with relevant departments.

\section{Dissemination Willingness (DW)}

If my friend is interested, then I am willing to spread the public opinion of campus emergencies to him/her.

If I find a discussion area similar to the public opinion of campus emergencies, then I will forward the information.

I will forward the public opinion of campus emergencies to my families and friends.

\section{Emotional Motivation (EM)}

I would like to express my concern and panic about the spread of the epidemic.

I would like to express my doubts about the relevant government departments and their measures.

\section{Adult Attachment (AD)}

I find that when I need help, no one would help me.

I want to be close to others, but I am afraid that I will be hurt. Being close to others makes me feel a little uncomfortable.

\section{Social Motivation (SM)}

I want to express my concern for the epidemic.

I want to express my concern for the people affected by the epidemic.

\section{Consciousness of Social Participation (CSP)}

I often take part in some social activitiess.

I believe that social activities will enrich my life.

I will actively share my experience in social activities.

\section{Risk Perception (RP)}

I think that the prevalence and spread of this epidemic are difficult to control.

I think that this epidemic disease is difficult to treat.

\section{GLOSSARY}

1. Adult Attachment (AA) is a sustained and long-term emotional connection between adult individual and current peers and a stable interpersonal interaction style of the individual. Adult attachment behavior is developed and maintained through a cognitive system that creates internal working models of relationships with others through relational experience (Bowlby's attachment theory, 1982/1969).

2. Affective Dispositions (AD) are dynamic, changeable, teachable, cultivable, and developmental qualities which are socially constructed and individually shaped (NCATE, Professional standards for the accreditation of teacher preparation institutions, Program 2008; Obara, Processes of Disposition Development in K-5 Teachers, 2009). AD could be categorized as desirable and undesirable.

3. Social Motivation (SM) is the psychological tendency of individuals to engage in certain activities to meet their own social needs, which is directly related to their social needs, but not to their physiological needs.

4. Emotional Motivation (EM) refers to the condition wherein people release public crisis information to express emotions. After the outbreak of a major epidemic, the public's psychology, emotion, and belief will be affected to different extents.

5. Average Variance Extracted (AVE) measure the average variance shared between a construct and its measures, and by calculating the correlations between different constructs. A matrix can then be constructed where the square root of AVE is in the diagonal, and the correlations between the constructs are in the off diagonal. For adequate discriminant validity, the diagonal elements should be greater than the off-diagonal elements in the corresponding rows and columns (70). 